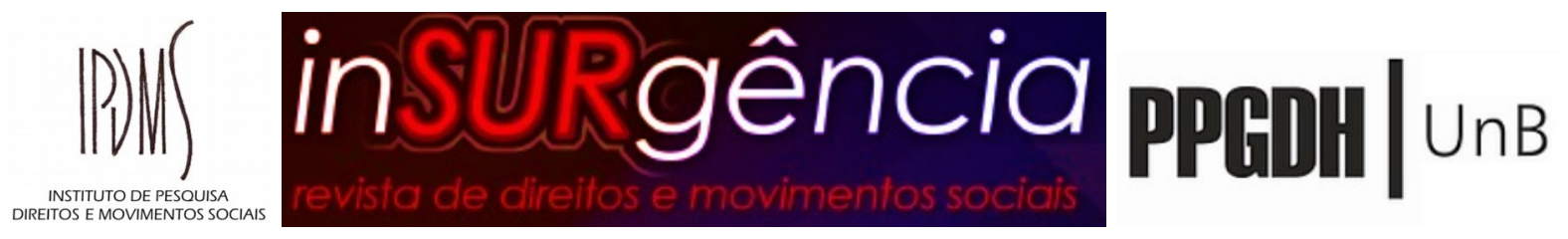

\title{
CONFLITOS FUNDIÁRIOS URBANOS
}

Anna Carolina Lucca Sandri ${ }^{1}$

Marcelo Eibs Cafrune ${ }^{2}$

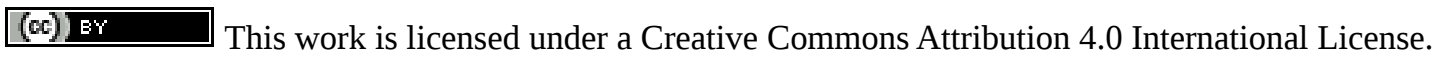

Os conflitos fundiários urbanos estão situados no âmbito da luta pela apropriação material dos territórios compreendidos como urbanos, ou em processo de urbanização. Frequentemente, tais conflitos tornam-se visíveis nas lutas por moradia, ou seja, nas reivindicações para a regularização fundiária, nas ocupações de imóveis urbanos vazios, em empreendimentos públicos e privados que intentam remover populações de baixa renda.

Em decorrência da reprodução socioterritorial das desigualdades, parte significativa da população é impedida de acessar à terra urbanizada e regular, por isso, os grupos sociais populares estão inseridos na maioria dos conflitos fundiários urbanos, que compreendem ocupações recentes contestadas imediatamente e ocupações tradicionais questionadas por fatos novos criados internamente à área ocupada, como reivindicações por investimentos em infraestrutura, ou externos a ela, que abarcam interesses do poder público para conferir outra destinação para o imóvel.

Dentre os fatores que construíram a atual realidade de impossibilidade de acesso formal à terra urbana, destacam-se: a desigualdade social histórica, a grande concentração de terras, os altos preços da terra urbana, a ausência de política pública de produção habitacional permanente e a impossibilidade de aquisição de terras via mercado formal pela classe trabalhadora - em razão da exclusão do custo da moradia do valor referente ao salário (OLIVEIRA, 2003).

Em geral, a ocupação irregular de imóveis urbanos destinados à moradia ou à ampliação de moradias em uma área já ocupada terá como motivação o seu valor de uso, que poderá ou não estar vinculado à sua localização. Em contrapartida, é recorrente que as áreas mais ameaçadas por remoções sejam aquelas para as quais se projetam valorização imobiliária,

1 Mestra em Direito (UFPR), graduada em Direito pela UFPR. Email: annaclsandri@gmail.com. ORCID:

2 Doutor em Direito (UnB). Professor de Direito Urbanístico na Universidade Federal do Rio Grande (FURG).

Email: marcelocafrune@furg.br. ORCID: 


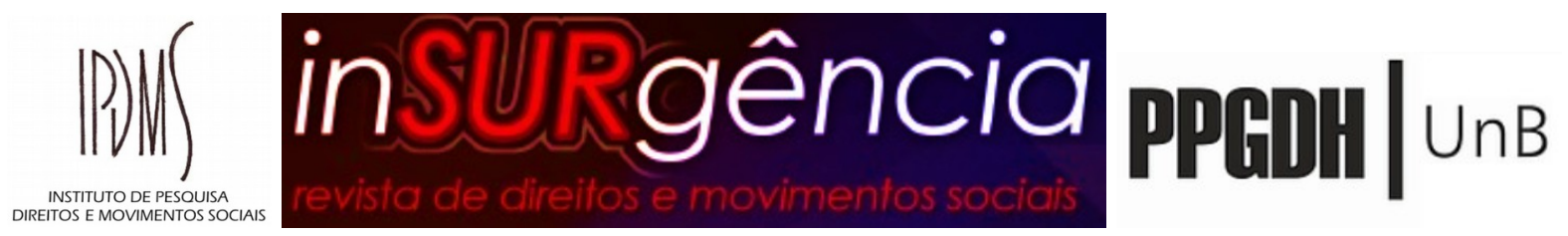

fundada, portanto, em valor de troca. Trata-se de uma disputa territorial pelo direito de possuir uma localização urbana.

Assim, importa definir o sentido econômico da localização nas cidades, já que os imóveis em regiões centrais têm preços mais elevados do que aqueles que se localizam em áreas periféricas. Sobre a determinação do valor do solo a partir da localização, João Sette Whitaker Ferreira afirma que:

esta se caracteriza pelo trabalho social necessário para tornar o solo edificável (a infra-estrutura urbana), as próprias construções que eventualmente nele existam, a facilidade de acessá-lo (sua 'acessibilidade’) e, enfim, a demanda. Esse conjunto de fatores é que distingue qualitativamente uma parcela do solo, dando-lhe certo valor e diferenciando-o em relação à aglomeração na qual se insere (FERREIRA, 2005, p. 5).

Considerando que o poder público realiza a atividade de planejamento urbano, sem que haja enfrentamento à especulação imobiliária, os grupos populares encontram dificuldades para adquirirem imóveis em regiões de localização privilegiada:

o próprio poder público torna-se criador privilegiado de escassez; estimula, assim, a especulação e fomenta a produção de espaços vazios dentro das cidades; incapaz de resolver o problema da habitação, empurra a maioria da população para as periferias; e empobrece ainda mais os pobres, forçados a pagar caro pelos precários transportes coletivos e a comprar caro bens de um consumo indispensável e serviços essenciais que o poder público não é capaz de oferecer (SANTOS, 2005, p. 123).

A partir desses aspectos, é que deve se pode compreender “os conflitos urbanos como todos os emaranhados de disputas advindos de uma construção desigual das cidades, com a distribuição de terras para moradia ocorrendo de forma negativa para as populações de baixa renda” (MAFRA; TROMBINI, 2017, p. 116).

Conforme destacaram Martins e Schavsberg:

é possível entender o conflito fundiário urbano como uma situação em que o sujeito dotado de legalidade sobre o imóvel (proprietário) o reivindica em face de outro com exercício da posse do mesmo (possuidor), que geralmente trata-se de uma coletividade em situação de hipossuficiência e vulnerabilidade jurídica e econômica (2019, p.3).

Nesses conflitos, o sujeito antagonista pode ser identificado pelo proprietário do imóvel ocupado, podendo ser um particular ou o poder público, que dispõem de inúmeros mecanismos políticos e jurídicos para confrontar a posse do bem.

Destaca-se o papel do Poder Judiciário, instituição para a qual os conflitos fundiários urbanos são levados para receberem soluções conforme o Direito e em que é usual a omissão 


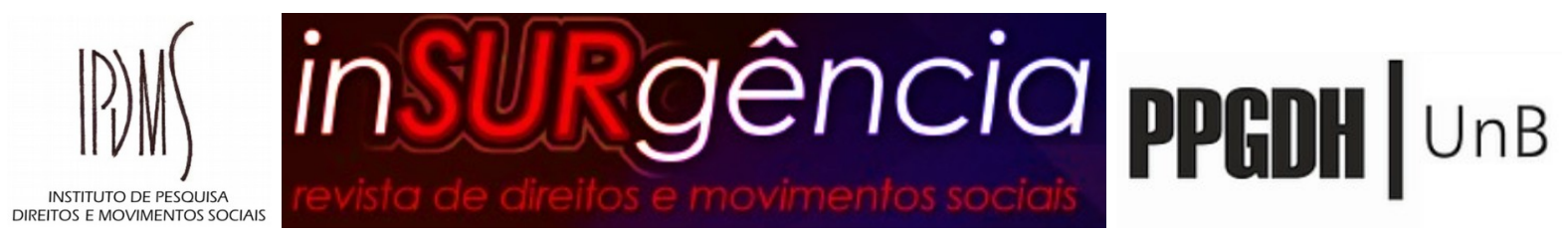

na aplicação dos instrumentos de proteção dos direitos humanos relativos ao direito à moradia, de modo que é expressiva a quantidade de decisões judiciais que consideram somente a validade formal do registro de propriedade do imóvel alvo do conflito, ignorando se a propriedade cumpre a sua função social (MILANO, 2016, p. 19).

Paralelamente, é importante frisar que a terra urbana também é suscetível de corrupção e apropriação ilegal, de modo que muitas vezes os supostos proprietários apresentam dificuldades para comprovar a propriedade do imóvel litigioso (COELHO; LUDERMIR, 2018, p. 18).

Dessa forma, o Poder Judiciário contribui para individualizar a realidade social, não considerando a dimensão coletiva e os conflitos sociais implícitos. Com isso, o processo judicial distancia-se da dimensão espacial que a constitui, corroborando a perspectiva de que o lugar disputado não influencia na decisão tomada pelo juiz:

\begin{abstract}
É a linha argumentativa mais comumente identificada nas decisões, que se caracteriza pela descontextualização do conflito fundiário coletivo de suas especificidades, tratando-o como disputa individual entre proprietários e não proprietários sob a guarida exclusiva do código civil e do respectivo diploma processual. Nessa forma de construção da solução jurisdicional, os conflitos são abordados de maneira simplificadora já que particularidades - como interesse social da demanda, quantidade de sujeitos atingidos com a remoção, dinâmicas socioespaciais de formação da ocupação informal - sequer são enfrentados na justificação decisória (MILANO, 2016, p. 168).
\end{abstract}

Outras linhas argumentativas de justificativa de remoções consistem na suposta ameaça ao meio ambiente promovida pelos ocupantes, notadamente em áreas de preservação ambiental e na interpretação do direito à moradia como norma programática, que somente poderia ser aplicada pelo Poder Legislativo ou Executivo:

Por diversas vezes o enfrentamento do argumento apresentado pelos réus acerca da violação do direito à moradia em função do despejo é afastado com a justificativa de que tal situação corresponde a um 'problema social' que não pode ser resolvido na seara do Poder Judiciário. Especialmente em detrimento do direito subjetivo do particular cuja propriedade tenha sido supostamente esbulhada por meio da invasão. A alegada 'abstratalidade' do direito à moradia é, assim, contraposta à solidez da necessidade de se salvaguardar a esfera patrimonial do particular. Ainda que sob percurso diverso, a estratégia permite que a decisão que autoriza a reintegração de posse se desincumba de discutir a repercussão social e o destino das famílias que serão despejadas. Isso seria tarefa e responsabilidade afeta à Administração Pública (MILANO, 2016, p. 173).

Outra constatação surgida do modo como o Poder Judiciário aborda os conflitos fundiários é de que a maioria desses conflitos não é submetido a uma análise mais detalhada 


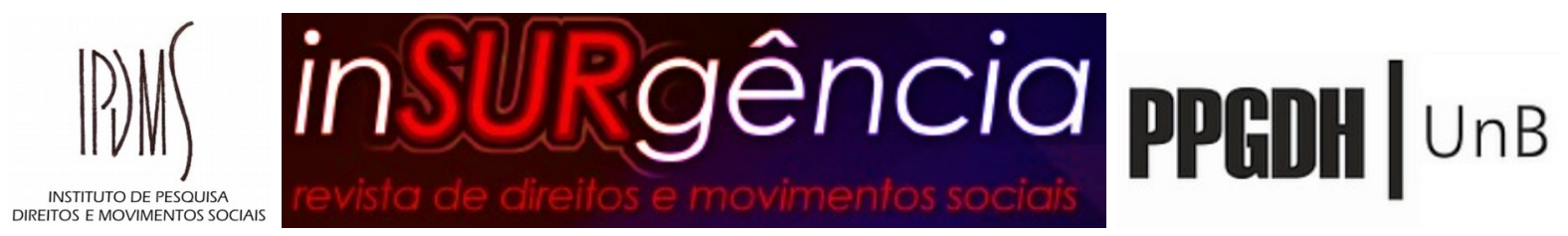

do mérito, já que o conteúdo material do litígio é esvaziado pela concessão de liminares, em que “a eliminação do local de moradia dos réus ocasiona a dispersão dos sujeitos em busca de soluções paliativas de moradia que tornem possível a sobrevivência, ocasionando a desintegração do grupo que anteriormente residia na área” (MILANO, 2016, p. 152).

Nesse sentido, depreende-se das decisões do Poder Judiciário, para além da defesa da propriedade, o desenvolvimento de mecanismos de seletividade, cujo ponto essencial situa-se na figura do ocupante/invasor, que, após construída, não permite saída jurídica possível.

Em razão dessa atuação seletiva promovida pelo Poder Judiciário, setores políticos articulados na defesa dos direitos dos ocupantes de imóveis em situação irregular defenderam propostas de institucionalização de políticas de mediação e prevenção de conflitos fundiários urbanos.

Dentre as iniciativas está a Resolução Recomendada nº 87/2009, do Conselho Nacional de Cidades, que conceituou conflito fundiário urbano como:

disputa pela posse ou propriedade de imóvel urbano, bem como impacto de empreendimentos públicos e privados, envolvendo famílias de baixa renda ou grupos sociais vulneráveis que necessitem ou demandem a proteção do Estado na garantia do direito humano à moradia e à cidade.

A Resolução indicava a centralidade da mediação como meio adequado para prevenir ações violadoras de direitos humanos, construir espaços de interlocução em que a tomada de decisão considere as causas do conflito e seus possíveis desdobramentos, de modo a respeitar o direito à moradia e considerar a função social da propriedade, bem como evitar abusos cometidos por agentes públicos e inibir decisões judiciais que fomentem despejos e remoções forçadas.

A opção pelos meios não judiciais para resolução de conflitos é resultante das limitações da tutela jurisdicional desses conflitos. Entre as críticas realizadas ao litígio judicial se encontram a morosidade do sistema de justiça, a não consideração da convivência futura das partes e a postura impositiva da autoridade judicial, entre outras.

Sem adentrar na temática da mediação, é importante apresentar as ressalvas feitas relativamente aos conflitos coletivos. Ana Lia Almeida apontou que a dimensão política e coletiva dos conflitos foi negligenciada por parcela significativa dos autores, os quais restringem a mediação dos conflitos à técnica, de forma que "é preciso enfatizar esta dimensão [política], para que suas causas mais profundas possam ser trabalhadas com vistas à superação do impasse numa perspectiva coletiva” (ALMEIDA, 2009, p. 50). 


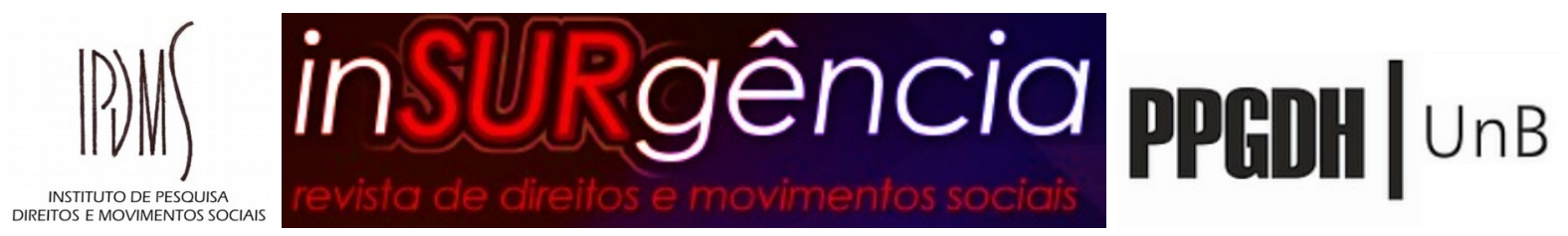

No início do século XXI, em distintos países da América Latina, houve um aumento expressivo de projetos vinculados com formas alternativas de resolução de conflitos. Ocorre que tais ferramentas devem também ser escrutinadas criticamente, haja vista a impossibilidade de soluções que contrariem interesses hegemônicos.

No caso de conflitos ambientais, Henri Acselrad assinalou que:

\begin{abstract}
em muitos casos originadas em instituições sediadas em países centrais e voltadas para a 'capacitação' de entidades e comunidades de países periféricos, tais iniciativas pretendem a difusão de modelos de análise e ação que pressupõem que a 'falta de instituições' está na origem dos conflitos ambientais e que a paz e a harmonia deveriam provir de um processo de despolitização dos conflitos por meio de táticas de negociação direta capazes de 'prover ganhos mútuos' (ACSELRAD, 2009, p. 94).
\end{abstract}

Essa estratégia política tem como objetivo psicologizar os dissensos e considerar como técnico o gerenciamento de situações que abarcam a confrontação de interesses que não podem ser compatibilizados, já que são próprios da arena política. Com isso, o intuito é de harmonizar as posições antagônicas, desconsiderando a raiz do problema nem incentivar a organização coletiva dos distintos grupos atingidos.

Com isso, os elementos políticos envolvidos são minimizados e os sistemas de governança extra-estatal dos conflitos são ampliados, retirando da esfera do conflito a contraposição entre direito e privilégio ou entre direitos distintos, sobre os quais o sistema judicial necessariamente deveria se manifestar. Ao mesmo tempo, a predisposição para a mediação equivale os desiguais, desconsiderando a legitimidade das suas posições e o viés transformador da resistência:

\footnotetext{
as tecnologias de formação de consenso são formuladas a fim de caracterizar todo litígio como um problema a ser eliminado. E todo conflito remanescente tenderá a ser visto como resultante da carência de capacitação para o consenso e não como expressão de diferenças reais entre atores e projetos sociopolíticos e territoriais a serem trabalhados no espaço público (ACSELRAD, 2009, p. 100).
}

Nesse sentido, pretende-se retirar a noção de justiça e injustiça da esfera pública, envolvidas em processos de reivindicações de direitos, e cujo foco consiste na capacidade de negociação para obter vantagens distribuídas conforme a habilidade dos sujeitos em conflitos, que pode ser sintetizada no esquema “ganha-ganha”. Por isso, o foco na mediação de conflitos tem como objetivo a diminuição da capacidade de resistência e articulação política das comunidades. 


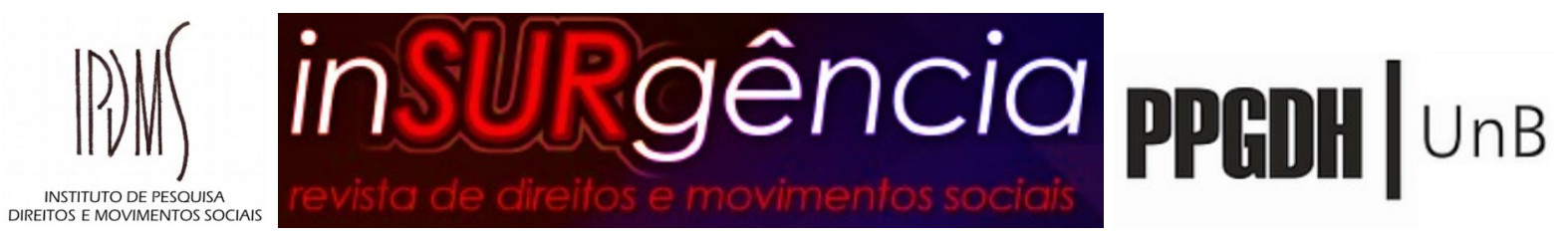

No tocante aos conflitos fundiários urbanos, a Resolução nº 87/2009, além da mediação de conflitos, estabelecia a adoção de políticas direcionadas para a prevenção desses litígios, definidas como:

\begin{abstract}
Conjunto de medidas voltadas à garantia do direito à moradia digna e adequada e à cidade, com gestão democrática das políticas urbanas, por meio da provisão de habitação de interesse social, de ações de regularização fundiária e da regulação do parcelamento, uso e ocupação do solo, que garanta o acesso à terra urbanizada, bem localizada e a segurança da posse para a população de baixa renda ou grupos sociais vulneráveis (CONSELHO DAS CIDADES, 2009).
\end{abstract}

Desse modo, a prevenção dos conflitos fundiários urbanos ocorreria mediante a implantação de políticas públicas executadas de forma satisfatória, enquanto a mediação de conflitos fundiários é um processo que envolve “as partes afetadas pelo conflito, instituições e órgãos públicos e entidades da sociedade civil vinculados ao tema, que busca a garantia do direito à moradia digna e adequada e impeça a violação dos direitos humanos” (CONSELHO DAS CIDADES, 2009).

Tais objetivos deveriam igualmente estar presentes na tomada de decisão pelo Poder Executivo, bem como nas decisões judiciais, seja em razão do disposto na Constituição de 1988, no Estatuto da Cidade (Lei Federal n. 10.257/2001), seja em atenção ao Direito Internacional.

Dentre as normativas produzidas no âmbito do Sistema Internacional de Direitos Humanos, destaca-se o Pacto Internacional de Direitos Sociais, Econômicos e Culturais (PIDESC), em razão dos Comentários Gerais n. $4^{\circ}$ e n. $7^{\circ}$, produzidos no âmbito do Comitê das Nações Unidas de Direitos Econômicos, Sociais e Culturais.

O Comentário Geral n. 4, aprovado pelo Comitê em 1991, define o conteúdo do direito à moradia adequada, em que se destaca o conceito de Segurança Jurídica da Posse, segundo o qual: “todas as pessoas devem possuir um grau de segurança da posse que lhes garanta a proteção legal contra despejos forçados, expropriação, deslocamentos, e outros tipos de ameaças”.

O Comentário Geral n. 7, aprovado em 1997, impõe limites ao arbítrio diante dos despejos forçados, por meio de algumas garantias processuais obrigatórias para que sejam considerados legais. Infelizmente, são poucos os exemplos de processos judiciais envolvendo conflitos fundiários urbanos no Brasil em que são impostos limites aos despejos e remoções forçados. 


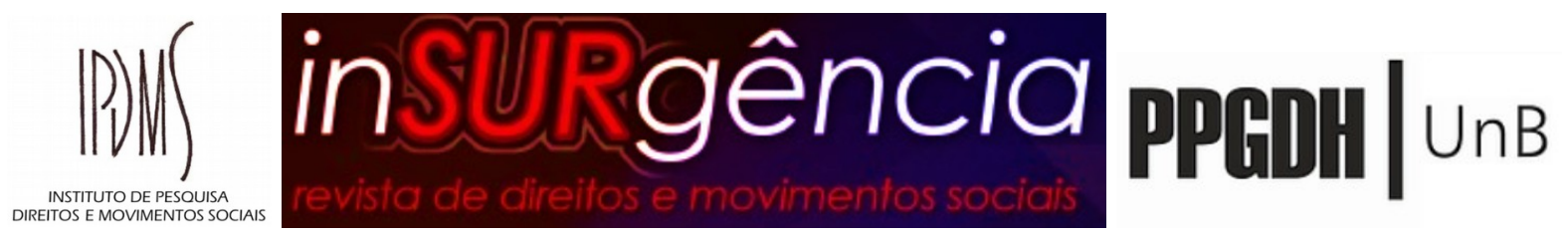

A Lei Federal n. 13.105, de 16 de março de 2015, que instituiu o novo Código de Processo Civil, previu a obrigatoriedade de realização de audiência de mediação pelo menos nos casos de posse velha (art. 565) e a obrigatoriedade de participação do Ministério Público e da Defensoria Pública nos casos de conflitos coletivos envolvendo população pobre (art. 565, $\left.\S 2^{\circ}\right)$.

Conforme diversas pesquisas têm indicado, a mudança na Lei não é suficiente para que haja uma mudança da atuação do Poder Judiciário:

A dinâmica com que o Judiciário encara as ações possessórias necessita de mudanças capazes de impedir que os juízes decidam sem observarem os valores contidos nos documentos internacionais de direitos humanos e na CF/88. Não resta dúvida que as remoções forçadas são uma ameaça à concretização de uma diversidade de direitos humanos fundamentais (CARVALHO; RODRIGUES, 2015, p. 1765).

Observando a atuação do Estado brasileiro para a institucionalização de políticas de mediação de conflitos fundiários urbanos, merece destaque também o Relatório da Pesquisa Sobre Soluções Alternativas para Conflitos Fundiários Urbanos, realizada pelo Instituto Pólis, no âmbito do Diálogos da Justiça, projeto para Fortalecimento da Justiça Brasileira, da Secretaria de Reforma do Judiciário, do Ministério da Justiça (POLIS, 2013).

Essa pesquisa, ao fazer um balanço da problemática, apontou para a necessidade de implementação de uma política nacional, bem como pra mudanças na legislação, sensibilização do Poder Judiciário, e por fim afirmou:

é preciso rever conceitos e pensamentos que parecem consolidados sobre determinados institutos no campo do Direito, em especial sobre o regime jurídico da posse, que quase sempre se confunde com o regime jurídico da propriedade. (...) [É] necessária a adoção de um regime jurídico da posse social e da função social da posse, da adoção jurídica do impacto social no mesmo patamar do impacto econômico e ambiental, da configuração de novas formas de proteção jurídica dos espaços territoriais onde vivem populações de baixa renda ou grupos sociais vulneráveis como um bem social no mesmo patamar de um bem comum ou ambiental (POLIS, 2013, p. 60).

No mesmo sentido, é a avaliação de Martins e Schavsberg:

o que se constata, em âmbito nacional é a significativa ausência de política efetiva para tratar o tema dos conflitos fundiários urbanos, fazendo com que, nos níveis estadual e municipal, estabeleçam-se políticas e entendimentos desconexos e frágeis em relação aos processos de remoção e reassentamento. Com efeito, não havendo uma diretriz nacional a ser seguida, existem variações e desvinculação das ações locais com uma política urbana nacional maior e criada no âmbito dos programas de regularização fundiária, dos planos de habitação de interesse social e ainda longe do 


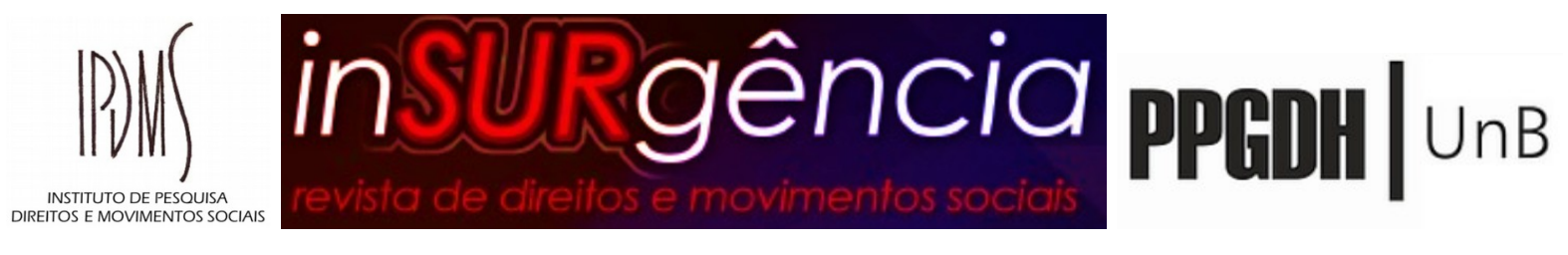

marco jurídico nacional de direito à cidade, representado pelo Estatuto da Cidade (2019, p. 15).

Em pesquisa desenvolvida pela organização de direitos humanos Terra de Direitos sobre algumas experiências pontuais de mediação de conflitos fundiários urbanos desenvolvidas no Brasil $^{3}$, verificou-se o não enfrentamento do mérito do processo, consequentemente não foram consideradas as matérias de regularidade fiscal e jurídica dos imóveis, assim como a função social da propriedade, ocasionando o favorecimento de interesses dos supostos proprietários e conduzindo para a reintegração dos ocupantes (MAFRA; TROMBINI, 2017, p. 71 e 88).

Sobre o resultado da mediação, nas experiências conduzidas pelo CEJUSC houve proprietários que não demonstravam nenhum interesse em negociar por considerarem a ocupação como ilegal. Contudo, também houve situações em que os proprietários estavam dispostos a dialogar sobre a permanência das famílias na área, geralmente envolvendo contrapartida monetária por parte dos ocupantes. Inclusive em determinadas situações esse acordo pode favorecer ao proprietário, visto que pode comprometer direitos que poderiam ser acessados pelos ocupantes pelas vias judiciais, como por exemplo, a realização de acordo para compra da área do proprietário quando os ocupantes teriam direito ao usucapião (MAFRA; TROMBINI, 2017, p. 57 e 85), ainda que deve ser considerada a morosidade existente nos processos de usucapião.

Desse modo, um dos possíveis resultados da mediação é a suspensão das ações de reintegração de posse, conferindo mais tempo para as partes, inclusive para oferecer alternativas habitacionais para as famílias, que podem consistir na permanência definitiva das famílias na área, na inserção em programas de aluguel social e na inserção em novos empreendimentos, portanto, um dos ganhos da mediação é um “despejo humanizado” (MAFRA; TROMBINI, 2017, p. 78 e 81).

Com isso, nas instâncias em que não é observado o direito à moradia, os resultados não podem ser qualificados como soluções ao conflito, apenas os gerindo, deslocando os ocupantes para outras regiões da cidade, ou seja, para outras ocupações ou mesmo para a rua:

É necessário observar que à medida que compreendemos o conflito fundiário coletivo como uma disputa pela terra, a maioria dos resultados apresentados não trata o conflito em si. Se o desfecho da mediação é conseguir mais tempo aos ocupantes, a solução é temporária ou, melhor dizendo, a desocupação protraída no

3 O estudo efetuado pela Terra de Direitos abrangeu as experiências da Mesa de Diálogo de Minas Gerais, vinculada ao Poder Executivo, o Grupo de Apoio às Ordens de Reintegração de Posse - Gaorp, em São Paulo, e o Centro Judiciário de Solução de Conflitos e Cidadania - CEJUSC, em Porto Alegre, ambos vinculados ao Poder Judiciário (MAFRA; TROMBINI, 2017, p. 10). 


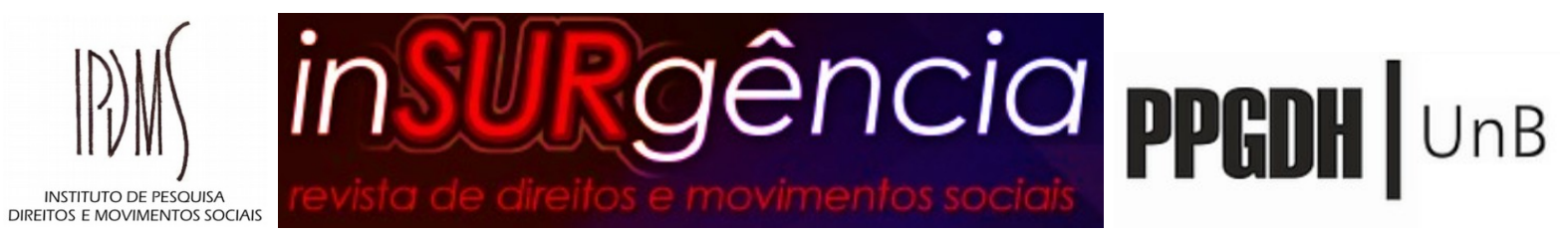

tempo. As instâncias que tenham sido capazes de ofertar alternativas de moradia, essas sim dão tratamento efetivo ao conflito trazido à mediação. Note-se que essa é a perspectiva da parte mais frágil da disputa, os moradores. Porém, se na visão dos demais integrantes das experiências supracitadas - poder público e proprietários - o objeto a ser tratado é a ocupação, vista como algo pernicioso, então as instâncias criadas satisfazem o objetivo colocado. É dizer: o conceito de conflito adotado reflete no tratamento oferecido (MAFRA; TROMBINI, 2017, p. 84 e 85).

Portanto, o melhor enfrentamento aos conflitos fundiários urbanos impõe a formação dos diversos sujeitos envolvidos no conflito, incluindo os órgãos administrativos, os poderes legislativo e judiciário para que a dimensão política e social desses conflitos possa ser compreendida pelos agentes públicos e para que sejam explicitadas as causas socioeconômicas que dão causa aos conflitos fundiários e que, no atual contexto de financeirização das cidades e da habitação, seguirão determinando a produção de cidades injustas e desiguais.

\section{Referências:}

ACSELRAD, Henri et al. O que é Justiça Ambiental. Rio de Janeiro: Garamond, 2009.

ALMEIDA, Ana Lia Vanderlei de. Mediação popular: o direito fundamental do acesso à justiça como prática emancipatória. João Pessoa: Programa de Pós-Graduação em Direito (Mestrado) da Universidade Federal da Paraíba, 2009.

CARVALHO, Cláudio Oliveira de; RODRIGUES, Raoni. O Novo Código de Processo Civil e as ações possessórias - novas perspectivas para os conflitos fundiários coletivos? In: Revista de Direito da Cidade. vol. 07, n. 4, 2015. Disponível em: http://www.epublicacoes.uerj.br/index.php/rdc/article/view/20912/15356. Acesso em: 15 fev. 2016.

COELHO, Ronaldo; LUDERMIR, Raquel. Terra e moradia: conflitos fundiários urbanos em Pernambuco. Recife: Habitat para a Humanidade Brasil, 2018.

CONSELHO DAS CIDADES. Resolução Recomendada nº 87, de 08 de dezembro de 2009. Recomenda ao Ministério das Cidades instituir a Política Nacional de Prevenção e Mediação de Conflitos Fundiários Urbanos. Diário Oficial da União. Brasília, DF, n. 98, 25 mai. 2010, Seção 1, p. 88-90.

FERREIRA, João Sette Whitaker. A cidade para poucos: breve história da propriedade urbana no Brasil. In: Anais do Simpósio “Interfaces das representações urbanas em tempos de globalização”, UNESP Bauru e SESC Bauru, 21-26 ago. 2005. Disponível em: http://www. usp.br/fau/docentes/depprojeto/j_whitaker/propurbcred.doc. Acesso em 11 set. 2011. 


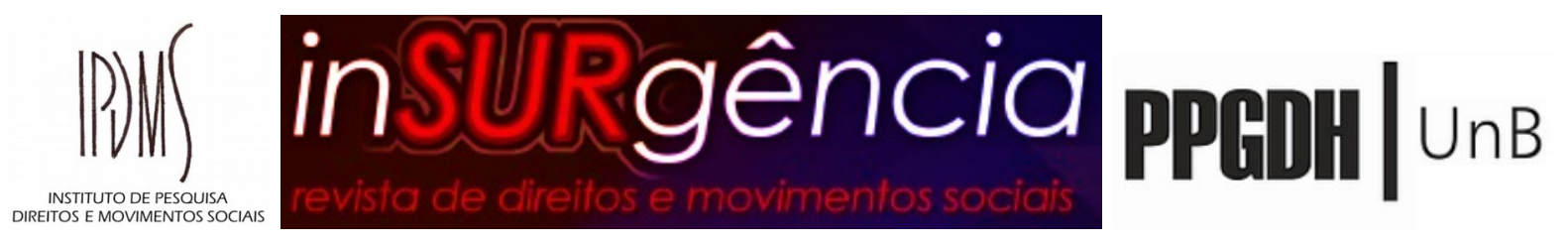

MARTINS, Jorge Lucien Munchen; SCHAVSBERG, Benny. Conflitos Fundiários Urbanos. In: Anais XVIII ENANPUR 2019. Disponível em: http://anpur.org.br/xviiienanpur/anais, Código verificador: U1ZIT6JdNyd7. 17 p. Acesso em: 13 jun. 2020.

MAFRA, Matheus; TROMBINI, Maria Eugenia. Diálogos sobre justiça e conflitos fundiários urbanos: caminhando da mediação para a efetivação dos direitos humanos. Curitiba: Terra de Direitos, 2017.

MILANO, Giovanna Bonilha. Conflitos fundiários urbanos e Poder Judiciário: decisões jurisdicionais na produção da segregação socioespacial. Curitiba: Programa de Pós-Graduação em Direito (Doutorado) da Universidade Federal do Paraná, 2016.

POLIS, Instituto. Relatório da Pesquisa sobre Soluções Alternativas para Conflitos Fundiários Urbanos. Governo Federal, Ministério da Justiça, Secretaria de Reforma do Judiciário, Programa das Nações Unidas para o Desenvolvimento (PNUD). São Paulo/ Brasília. jul. 2013. Disponível em: http://www.polis.org.br/uploads/2134/2134.pdf. Acesso em: 06 fev. 2016.

OLIVEIRA, Francisco de. Crítica à Razão Dualista / O ornitorrinco. São Paulo: Boitempo, 2003.

SANTOS, Milton. A urbanização brasileira. 5. Ed. São Paulo: Edusp, 2005.

Submetido em 18/07/2020.

Aprovado em 18/07/2020. 